therapeutic benefit, and the proposed expansion continues in the main to address marginal therapeutic areas. But selected lists are only one approach to reducing prescribing costs. What is needed is an overall strategy that addresses the way that drugs are priced, how they are marketed, and the artificial division between funding and pricing of drugs in hospital and primary care.

With increasing downward pressure on prescribing budgets, general practitioners may be expected to save money by prescribing generically and using treatment protocols that take the cost of drugs into account. The revised selected list may help them to make a small proportion of the savings that are needed. As individual companies have been given the right to make representations to the advisory committee the list may not emerge for some months.

This still leaves the question of what we should look for in a new selected list. Obviously, effective "best buys" should be available on NHS prescription in all therapeutic areas. As with the present list some products may in future be allowable on NHS prescription only if prescribed generically: this will not harm patients or doctors, though it will have financial consequences for some companies. Some of these concerns could be addressed through the Pharmaceutical Pricing Regulations Scheme, although this will reduce the possible financial savings. Some patients and doctors may not continue to have their favourite preparation available on the NHS, with most controversy likely to arise from any limitation of the range of oral contraceptives.

Doctors need to concentrate on their prescribing policies where growth in the volume and cost of prescriptions has been high and marketing aggressive and the therapeutic advantage of new products is questionable. New drugs for depression, asthma, peptic ulceration, and hyperlipidaemia fall into this category. The selected list is not the solution to the problem of escalating prescribing costs, and the danger is that it will distract prescribers from what they need to do. Finally, it seems likely that the expanded list will be introduced too late this financial year to have anything like its intended financial impact.

D N BATEMAN

Wolfson Unit of Clinical Pharmacology, Reader in therapeutics

University of Newcastle upon Tyne,

Newcastle upon Tyne NE1 4LP

1 Deitch R. A limited NHS drug list. Lancet 1984;ii:1166.

2 Russell W. DHSS: absolute determination on a limited list. BMf1984;289:1467.

3 Griffin J, Taylor D. Why a limited NHS medicines list would harm Britain. Pharm f1985;234:38-9.

4 Rayner B. Changes to the selected list scheme regulations for NHS drug prescribing. London: Department of Health, 1990. (EL(90)220, FPN 526 (1990).)

5 Department of Health. Virginia Bottomley outlines way forward on controlling increase in NHS drug bill. London: DoH, 1992. (Press notice H92/430.)

6 Department of Health. Action to limit NHS drugs bill will not affect patient care says Virginia Bottomley. London: DoH, 1992. (Press notice H92/385.)

7 More cost-cutting in UK? Scrip1993 Feb 16:2.

8 ABPI. What the new limited list will mean for NHS patients and the British pharmaceutical industry [advertisement]. New Statesman and Society 1993 March 12:4.

\title{
Special needs of elderly diabetic patients
}

\author{
Many are losing out by default
}

Diabetes is common in elderly British people, with a prevalence of between $3 \%$ and $6 \% .^{12}$ Elderly (mainly noninsulin dependent) diabetic patients therefore represent the largest sector of the diabetic population, with several thousand in an average health district. ${ }^{13}$ Nearly a decade ago it was recognised that diabetes in elderly people was neglected and that many patients were being denied specialist care until a medical crisis supervened. ${ }^{4}$ Several recent community studies of diabetes have also shown that these patients suffer a disproportionate burden of ill health and are responsible for increased economic and social demands on society. ${ }^{56}$ These studies provide evidence that diabetes in elderly people is associated with inadequate and unstructured care, severe disability, and many unmet needs.

The belief that diabetes in older patients is a mild disease is wrong. One survey showed that microangiopathic complications were as common as in younger patients but macroangiopathy (such as ischaemic heart disease) was significantly more common. ${ }^{5}$ In addition, elderly diabetic patients have more complications at the time of diagnosis, with retinopathy being detectable in over $10 \% .^{7}$ Whether diabetes in elderly patients is a different disease from that in younger patients is arguable, ${ }^{8}$ but some complications such as diabetic amyotrophy and hyperosmolar non-ketotic coma occur mainly in elderly diabetic patients. Coexisting and often chronic medical problems such as cerebrovascular disease, arthritis, Parkinson's disease, and dementia exacerbate the impact of diabetes, increase the level of disability, and hinder management.

The view that the only aims of treatment in this group are relieving the symptoms of hyperglycaemia and preventing hypoglycaemia is outmoded. ${ }^{9}$ Increased life expectancy means that many elderly diabetic patients live long enough to suffer from disabling (potentially preventable) complications such as blindness, foot ulceration, and lower limb amputation.

Given the special demands of these patients, can busy diabetic clinics meet their needs? Time is required not only to consider glycaemic control but also to discuss problems such as increased immobility and dependency, transfer to a residential or nursing home, and so on. To cope with these, doctors require training and experience in rehabilitation and medical care of elderly people as well as diabetes. In addition, there may be no systematic follow up of these patients, as who is primarily responsible for their management (diabetologist, general physician, geriatrician, or general practitioner) is unclear. Poor follow up means inadequate screening for complications, failure to provide sufficient information and education to both patients and carers, and an increased rate of admission to hospital. ${ }^{10}$

How can we improve the future delivery of diabetic care to this large and vulnerable group of patients? Firstly, we need to recognise that management must include assessing the impact of coexisting disease and maintaining the patient's wellbeing and quality of life. More emphasis should be placed on screening programmes, which will require cooperation among the hospital doctor, general practitioner, diabetes specialist nurse, and district nursing service as well as the patient and carer. Annual screening programmes should be established for foot problems and for visual problems, with special attention being given to visual acuity, diabetic retinal disease (especially maculopathy), and cataracts. These screening services should be incorporated into educational programmes specially tailored for elderly patients and their carers. Realistic and achievable goals for glycae- 
mic control should be agreed between patient and doctor.

Although many elderly diabetic patients can be managed in primary care, closer liaison between general practitioners and hospital doctors is likely to be beneficial. In each locality or district, guidelines for managing diabetes should be agreed between interested parties, and these should be supported by adequate documentation, computerisation of information, and clinical audit. A simple mechanism should exist to ensure that elderly diabetic patients who require consultation with a consultant (for example, those with serious diabetic complications or those requiring insulin) receive it. Geriatricians can manage many elderly diabetic patients, especially those with increasing dependency and multiple medical problems, but they will require training in diabetes to do this well. Rather than setting up diabetic clinics for elderly patients it may be more appropriate for a geriatrician to join the diabetic team, allowing the concentration of resources and ready access to support services required for the care of elderly patients.

These strategies may help to meet the needs of this important sector of the diabetic population, but to be effective they must begin at an early stage of the disease and be adequately funded. It is hoped that the enthusiasm for implementing the St Vincent declaration, which recommends ways of reducing the substantial toll of complications such as amputation, renal failure, and blindness in the diabetic population, ${ }^{11}{ }^{12}$ will also take on board the special problems of elderly diabetic patients.

ALAN J SINCLAIR

Senior lecturer

University Department of Geriatric Medicine,

Cardiff Royal Infirmary,

Cardiff CF2 1SZ

University Department of Medicine,

Birmingham Heartlands Hospital,

Birmingham B9 5SS

1 Neil HAW, Gatling W, Mather HM, Thompson AV, Thorogood M, Fowler GH, et al. The Oxford community diabetes study: evidence for an increase in the prevalence of known diabetes. community diabetes study:

2 Croxson SCM, Burden AC, Bodington M, Botha JL. The prevalence of diabetes in elderly people. Diabetic Med 1991;8:28-31.

3 Samanta A, Burden AC, Fent B. Comparative prevalence of non-insulin-dependent diabetes mellitus in Asian and white Caucasian adults. Diabetes Res Clin Pract 1987;4:1-6.

4 Tattersall RB. Diabetes in the elderly-a neglected area? Diabetologia 1984;27:167-73.

5 Neil HAW, Thompson AV, Thorogood M, Fowler GH, Mann JL. Diabetes in the elderly: the Oxford community diabetes study. Diabetic Med 1989;6:608-13.

6 Dornan TL, Peck GM, Dow JDC, Tattersall RB. A community survey of diabetes in the elderly. Diabetic Med 1992;9:860-5.

7 Caird FL. Complications of diabetes in old age. In: Evans JG, Caird FL, eds. Advanced geriatric medicine. London: Pitman, 1982:3-9.

8 Morley JE, Mooradian AD, Rosenthal MJ, Kaiser FE. Diabetes mellitus in elderly patients-is it different? YAMA 1987;83:533-44.

9 Sinclair AJ. Diagnosis and early management of type 2 diabetes in the elderly: a 1990s perspective. Care of the Elderly 1993:5:69-72.

10 Boulton AJ. Update on long-term diabetic complications. In: Lewin IG, Seymour CA, eds. Current themes in diabetic care. London: Royal College of Physicians of London, 1992:45-53.

11 World Health Organisation and European Region of International Diabetes Federation. The St Vincent Declaration. Copenhagen: WHO Europe and European Region of the IDF, 1989. 12 Alberti KGMM. The health of the nation: role of diabetes. BMJ 1991;303:769-72.

\section{WHO at the crossroads}

\section{Will it embrace the necessary reforms?}

The World Health Organisation is at a turning point in its 45 year history. This week its 183 member states will decide whether its director general, Dr Hiroshi Nakajima, should continue in office for a second five year term despite allegations of mismanagement and clear signs of the organisation's fall in influence under his leadership.

WHO is faced with growing challenges and falling funds: its overall budget fell by a tenth in real terms over the past 10 years. AIDS, environmental degradation, and the spread of smoking in the developing world are now added to old health problems-such as tuberculosis and malaria-that WHO has so far failed to solve. Despite a biennial budget of over $\$ 26 \mathrm{~m}$ for malaria programmes the disease is still endemic in 93 countries and kills between 1.5 and 3 million people a year. Tuberculosis, once thought to be under control, now kills a similar number each year ( $\left.\mathrm{p} 1147^{1}\right)$

The heady days of eliminating smallpox are over, and WHO's donors are becoming increasingly critical of the organisation. They criticise its fixation on medical technology-vaccines, drugs, and doctors-and its unwillingness to grapple with the practicalities of delivering health care. Critics would like to see a move away from medical and scientific experts, who make up nearly a fifth of WHO's staff of 4500, towards employing more economists and administrators. They believe that WHO should be helping to tackle the root cause of most disease-poverty-and doing more to improve the infrastructure of health care in the developing world.

WHO faces massive problems inherent in any large international bureaucracy. Run by UN civil servants its internal workings remain closed and cumbersome, and it escapes the moderating influence of public accountability and scrutiny from the international press. In addition, a system that must be seen to be achieving fair and balanced representation of all member states risks breeding committees high in make-weights. Political considerations are likely to take priority over finding the best person for the job.

Dr Nakajima's re-election in January by the organisation's executive board, against the unprecedented opposition of every major donor nation except Japan, was a prime example of national interests being put above the international good. According to Western diplomats, the Japanese government carried the vote by threatening to withdraw trade and aid agreements from poorer countries if their representatives on the executive board did not vote for Nakajima. The desire to uphold national pride is one explanation for Japan's unstinting support for a man whose first term in office was characterised, say his critics, by an autocratic style, poor communication, and numerous appointments of inappropriate people to the organisation's staff. As he is reaching retirement age he could easily have stood down gracefully. Even senior Japanese members of staff have joined the clamour for Nakajima's removal; one of them in a recent letter to Japan's foreign ministry used words such as "nightmare" and "catastrophe" to describe the likely outcome if he stays.

The past two months have seen further damaging allegations against him. Although the organisation's external auditor rejected allegations of corruption, it found that the number of contracts let to members of the executive board had doubled and their value trebled in the six months leading up to the election. Disappointed though Dr Nakajima's opponents are by the auditor's main conclusions they can still point to the shortcomings in management and disregard for the organisation's rules also highlighted in the report.

Dr Nakajima's response to these criticisms has been to 